\title{
АКТИВИЗАЦИЯ САМОСТОЯТЕЛЬНОЙ РАБОТЫ СТУДЕНТОВ НА ОСНОВЕ ЭКЗИСТЕНЦИАЛЬНО-ГУМАНИСТИЧЕСКОЙ КОНЦЕПЦИИ ЛИЧНОСТНО-ЦЕНТРИРОВАННОГО ОБУЧЕНИЯ В ВУЗЕ
}

Берберян А.C.

В статьерассматриваются актуальные проблемы исследования самостоятельной работы студентов как высшей формы учебной деятельности, а также приведены результаты эмпирического исследования. Особое внимание уделяется роли самостоятельной работы вличностном и профессиональном самоформировании.

Ключевые слова: самостоятельная работа студентов, личностное и профессиональное самоформирование, личностно-центрированная концепчия обучения.

Сфера образования, оперативно реагируя на все изменения в обществе, принимает на себя вызовы времени, модернизируя систему образования и вооружая нынешнее поколение современными знаниями и технологиями, «дает ему первотолчок к саморазвитию, ту интенцию, благодаря которой человек будет искать и раскрывать смыслы своей жизни» [1, с. 71], тем самым, обеспечивая его конкурентоспособность на международном рынке. Кардинальное значение для сферы высшего образования имеет провозглашенный С.Д. Смирновым принцип: от деятельности к личности, который содержит мощный потенциал реализации в практике высшей школы [7]. Интересной с точки зрения концептуального подхода и технологических разработок к развитию личности представляется идея развития «культуры достоинства» А.Г. Асмолова [3].

Гуманистическое личностно-центрированное вузовское обучение утверждает обучающегося в роли активного, сознательного, равноправного участника учебно-воспитательного процесса. Технология личностно-центрированного обучения вбирает в себя достижения гуманистических мировоззренческих идей и демократичекого образа жизни. Она основана на распространении идей гуманизации образования, согласно которым человек признается высшей ценностью (C.R. Rogers, 1961; A. Maslow, 1968, 1975; R. May, 1983; V.E. Frankl, 1988; J.F. Bugental, 1981; M. Boss, 1982; L. Binswanger, 1962; Н.A. Бердяев, 1990).

Практика гуманистической мысли отражает конкретные формы и методы личностно-ориентированного обучения (С.Д. Смирнов, И.В. Абакумова, 2006; П.Н. Ермаков, 2006; А.Г. Асмолов, 2002; Д.А. Леонтьев, 2006; И.С. Якиманская, 1996; И.Б. Котова, А.В. Петровский, 1997; В.В. Сериков, 1997 и др.). В обобщенном виде они могут быть представлены по следующим параметрам: дифференциация учебновоспитательной деятельности; индивидуализация процессов воспитания и обучения; создание благоприятных условий для развития способностей каждого воспитанника; формирование однородных по совокупности признаков гомогенных 
групп; комфортность учебно-воспитательной деятельности; социальная безопасность, защищенность обучающихся; вера в ученика, его силы и возможности; принятие ученика таким, какой он есть; изменение целевой установки учебного процесса; обоснованность уровня развития каждого обучащегося; переориентация внутренних личностных установок преподавателя; усиление гуманитарного образования. Преимущества обучения по данным критериям весьма привлекательно сформулированы; среди преподавателей находятся немало энтузиастов и сподвижников, желающих следовать этим принципам.

Однако реалии армянской образовательной системы не позволяют использовать в чистом виде предлагаемые технологии: преподаватель не свободен в выборе методов и форм обучения. В реальной учебной деятельности преподаватель вынужден ориентироваться и во главу своей деятельности поставить успеваемость как результат, и дисциплину как атмосферу исполнительства и комфорта. Значимые аспекты личностно-центрированной технологии, внедряемые в практику армянской реальности, - гуманизация учебно-воспитательного процесса, поворот к личности обучающегося, внедрение конкретных методик и приемов, облегчающих и ускоряющих обучение [2]. Мы постараемся в соответствии с собственной концепцией и моделью вузовского обучения расставить акценты следующим образом:

1) цель личностно-центрированного обучения - акцентирование внимания на развитии ценностно-смысловой сферы;

2) отход от концепции формирования личности и утверждение концепции содействия ее развитию;

3) студент - субъект не учения, а жизни;

4) работа преподавателя направлена на удовлетворение потребностей личности;

5) справедливость в действиях преподавателя;

6) действенная помощь преподавателя, а не показной интерес к личности студента;

7) движущие силы учебно-воспитательного процесса - взаимодействие личности с личностью;

8) усиление диалогового характера общения преподавателя со студентами;

9) духовное общение со студентами;

10) личностно значимая цель деятельности;

11) знание пути достижения цели;

12) выбор индивидуальной траектории развития;

13) положительная оценка, поддержка со стороны преподавателя;

14) возможность выбора;

15) собственная ответственность студента;

16) изучение личных качеств студентов и динамики их развития;

17) поддержка положительных тенденций в развитии личности;

18) помощь в преодолении отрицательных тенденций.

Нужно отметить, что следование этим принципам приводит к изменениям в личностной сфере участников учебно-воспитательного процесса, которые, 
в свою очередь, диктуют необходимость подготовки, способствующей самосовершенствованию в процессе жизнедеятельности. Технология формирования гуманистической позиции приводит естественным образом к технологии саморазвития. Программа саморазвития преподавателя обязательно содержит оценку психолого-педагогических способностей развития, нравственно-ценностной сферы, прогностических умений.

На практике обычно большинство преподавателей в вузе хорошо подготовлены к обучению студентов и недостаточно - к их профессионально-личностному развитию; они активно включены в процесс обучения, но сознательно самоустраняются от участия во втором. Преобладающее большинство опрошенных преподавателей считает, что для участия в профессиональном развитии студентов надо работать во внеаудиторные часы, на что у них нет ни времени, ни сил, ни стимулов. В действительности такое мнение свидетельствует о неадекватном представлении преподавателей об организации и методике учебно-воспитательного процесса, не требующем дополнительных затрат времени. Важнейший источник максимальной интенсификации учения обучающихся и помощи в профессиональном самоформировании - активизация самих студентов. Все компоненты профессионализма - всегда продукт собственных усилий обучающихся. Ошибочно представление преподавания как передачи готового знания, а обучения как воспроизведения и запоминания, (нечто вроде «учебной воронки», в которую «заливают» знания) - это своего рода психолого-педагогический примитивизм. Обучение эффективно, когда представляет собой активную, психологически насыщенную деятельность обучающегося именно как самостоятельной личности. Важно, чтобы побуждения к полноценному овладению профессионализмом возникали не под нажимом извне, а порождались бы психологически, личностно, «изнутри». Образовательная система создает условия для обучения, приводящие к необходимым профессиональным изменениям в личностном развитии студента. Но решающей является активность самого субъекта обучения - студента, характеристики этой активности. Каждый оказывается в итоге образованным настолько, насколько занимается сам, и развитым как личность настолько, насколько стремится быть личностью. Необходимо создать систему стимулов к самоформированию, ибо невозможно сделать человека таким, каким он не хочет быть. Немаловажно обеспечить такой стиль работы в вузе, при котором все думают не о том, как заставить студента учиться, а о том, как создать такую обстановку, чтобы ему самому хотелось учиться. Без желания учиться обучение психологически приобретает для студентов характер внешне навязанной и чуждой его интересам работы, нужной только самим преподавателям.

Наибольший интерес в плане психологического анализа учебной деятельности представляет самостоятельная работа студента. Именно в ней более всего могут проявляться его мотивация, самоорганизованность, самоконтроль и творческие способности. Именно самостоятельная работа, на наш взгляд, может служить основой перестройки позиций студента в учебном процессе с позиции пассивного потребителя на позицию активного творца. 
В настоящее время самостоятельная работа обучающихся является одной из важных и широко обсуждаемых проблем преподавания в вузе. В исследованиях, посвященных планированию и организации самостоятельной работы студентов (Л.Г. Вяткин, М.Г. Гарунов, Б.П. Есипов, В.А. Козаков, И.Я. Лернер, Н.А. Половникова и др.), рассматриваются общедидактические, психологические, организационнодеятельностные, методические, логические и другие аспекты этой деятельности, однако особого внимания требуют вопросы мотивационного, процессуального, технологического обеспечения самостоятельной, аудиторной и внеаудиторной познавательной деятельности студентов. При достаточно многостороннем освещении вопросов этой проблемы психологическая сторона остается наименее представленной. Определение самостоятельной работы нуждается, на наш взгляд, в более четком формулировании. В общем случае, это любая деятельность, связанная с воспитанием мышления будущего профессионала, с зарождением самостоятельной мысли, с познавательной активностью студента как в учебной аудитории, так и вне ее, в контакте с преподавателем и в его отсутствии. В данной трактовке самостоятельная работа - более широкое понятие, чем домашняя работа. Она должна рассматриваться как специфическая, высшая форма учебной деятельности, форма самообразования, свободная по выбору, внутренне мотивированная деятельность [4], осознанная таким образом самим студентом.

Высшая школа отличается от средней главным образом - методикой учебной работы и степенью самостоятельности обучаемых. Соотношение времени, отводимого на аудиторную и самостоятельную работу, во всем мире составляет 1:3,5. В зависимости от типа задач в учебной деятельности различают репродуктивный уровень самостоятельной деятельности (выполнение заданий по образцу); реконструктивный уровень (составление плана, тезисов, рефераты) и творческую самостоятельную работу, требующую новых подходов к решению проблем [6].

Мы считаем, что подлинно самостоятельная работа как самостоятельная учебная деятельность может возникнуть на основе «информационного вакуума». Основное отличие самостоятельной работы от «внеурочной», «домашней» состоит в том, что в ее основе всегда лежат новые познавательные задачи. Естественно, нельзя рассчитывать на то, что истинно самостоятельной работой будут заниматься все, это было бы нереально, но создание условий и предпосылок для развития познавательных интересов студентов - есть проявление развивающего обучения в полном смысле этого слова. Требования добровольности, активности, участия студентов целесообразно поставить в основу организации самостоятельной работы студентов. Проблема упирается в формирование мотивации познавательных интересов, в организацию саморегуляции.

Мы провели эмпирическое исследование со студентами младших и старших курсов факультетов «Психология», «Экономика», «Туризм и реклама» РАГУ (Российско-Армянского государственного университета) с целью определения ценностно-профессиональной ориентации личности студента. 
Среди факторов, мешающих раскрыть потенциал и достичь высокой академической успеваемости, студенты единодушно произвольно назвали лень. В самом общем виде лень - это реакция личности на несоответствие требованиям ситуаций субъективному смыслу этих требований. Внешне эта реакция проявляется как отказ или уклонение от деятельности, а внутренне - как переживание невозможности устранить требуемое соответствие. Психодиагностический комплекс, выявляющий особенности проявления лени, включал методики: «Самооценка лени», «Незаконченные предложения», «Ассоциативный эксперимент», рисуночная проба «Моя лень», анкета «Саморегуляция». По результатам исследования, проведенного со студентами различных факультетов РАГУ, лень выступает как многоаспектный жизненный феномен, имеющий положительный и отрицательный смысл. Чаще всего лень связывается с ощущением состояния расслабления; ассоциативный ряд включает такие понятия, как отдых, развлечения (66 \%), как норма жизни (25\%), реже - как кризис и искушение (8 \%), и ни разу - как символ свободы и счастья. Индекс самоидентификации - 3,1 - степень осознанности собственной лени достаточно выражена. По шкале измерения лени данные результаты подтверждаются. По данным исследования причинами лени являются:

-отсутствие интереса - 58,3\%,

-особенности состояния $-41,6 \%$,

-дефицит возможностей - $0 \%$,

-внешнее давление - $0 \%$.

Работоспособность и устойчивость к монотонии сравнительно низкая. В учебной деятельности проявляется низкая способность к преодолению лени за счет саморегуляции, в сфере развлечения достаточно выражена способность в преодолении лени, достаточно высокий уровень саморегуляции.

Склонность к лени как нарушение саморегуляции, на наш взгляд, определяется отсутствием желания проявить активность, что связано, в свою очередь, с отсутствием познавательных интересов, несформированной готовностью к обучению, неумением использовать приемы саморегуляции в учебной деятельности.

Очевидно, что в процессе организации самостоятельной работы должна быть принята во внимание специфика самого учебного предмета. В то же время организация самостоятельной работы поднимает целый ряд вопросов, касающихся готовности студентов как субъектов деятельности.

В ходе эмпирического исследования по результатам разработанной нами анкеты мы выявили, что большинство студентов признают, что не умеют правильно организовать и распределять свое время. Результаты анкеты «Планирование» выявляют особенности планирования студентами временной перспективы, отражающего личностный ценностно-смысловой аспект времени. Незначительное количество студентов в обеих группах, планирующих на «сейчас», следовательно, менее концентрирующихся на данном промежутке времени, чем те, кто планирует на год, неделю.

Приемы осмысления, переработки, интерпретации и фиксирования необходимой учебной информации вызывает у студентов существенные затруднения. 
Но дело в том, что знание приемов обучения не является достаточным условием для эффективной самостоятельной работы. Эта способность самопроизвольно формируется только у студентов, обладающих положительной учебной мотивацией. К приемам обучения, стимулирующим личностное и профессиональное самоформирование, относятся:

-приемы культуры чтения (так называемого «динамического чтения»), культуры слушания;

-приемы краткой и рациональной записи (планы, тезисы, конспекты, аннотации и т.д.);

-общие приемы запоминания (приемы мнемотехники, структурирования учебного материала);

-приемы сосредоточения внимания, основывающиеся на использовании студентами различных видов самоконтроля;

-общие приемы поиска дополнительной информации (работа с библиографическим материалом, справочными каталогами);

-приемы подготовки к экзаменам, зачетам и различным видам работ;

-приемы эмоциональной саморегуляции;

-приемы рациональной организации времени, разумного чередования труда и отдыха.

Нам думается, что необходимо совместно с преподавателями составить специальные программы обучения самостоятельной работы, включающей определение цели самостоятельной работы, диагностирование собственных познавательных способностей, интеллектуальных, личностных и физиологических возможностей, объективную оценку временного параметра.

Студенту в вузе необходимо осмысление своих задач по самоформированию, по воплощению их в четко выраженный, интенсивно и оптимально осуществляемый лично обучающими процесс, который должен быть важнейшей и плодотворной частью всего образовательного процесса. Исходная проблема заключается в зарождении и всемерном усилении мотивов к профессиональному самоформированию обучающихся в намеренном, сознательном и постоянном «встревоживании внутренних источников саморазвития» [5].

В связи с этим можно выделить условия, обеспечивающие успешное выполнение самостоятельной работы:

1) мотивированность учебного задания;

2) осмысление познавательных задач, раскрытие смыслов научных понятий и категорий;

3) определение видов консультационной помощи (установочные, тематические, проблемные консультации);

4) выявление логических связей, определение практической значимости.

Самостоятельная работа включает воспроизводящие и творческие процессы в деятельности студента. В зависимости от этого различают три уровня самостоятельной деятельности студентов. 
1. Репродуктивный уровень - самостоятельная работа выполняется по образцу.

2. Реконструктивный уровень - могут выполняться рефераты.

3. Творческий, поисковый уровень - решение учебно-исследовательских заданий, курсовых и дипломных проектов.

Для организации и успешного функционирования самостоятельной работы студентов необходимо сочетание всех уровней самостоятельной работы.

В настоящее время в вузах существуют две общепринятые формы самостоятельной работы. Традиционная, т. е. самостоятельная работа, выполняемая самостоятельно в произвольном режиме времени и удобные для студента часы, часто вне аудитории, а когда того требует специфика дисциплины - в лаборатории или мастерской. Другой вид самостоятельной работы - аудиторная самостоятельная работа под контролем преподавателя, у которого в ходе выполнения задания можно получить консультацию. В настоящее время наметилась тенденция к разработке третьего, промежуточного варианта самостоятельной работы, предусматривающего большую самостоятельность студентов, большую индивидуализацию заданий [6].

Нижеприводимые рекомендации помогут преподавателям найти индивидуальный подход к студентам с различными характерологическими данными:

-аудиторные занятия следует проводить так, чтобы обеспечить безусловное выполнение некоторого минимума самостоятельной работы студентами (СРС) и предусмотреть усложненные задания для учащихся, подготовленных лучше; -необходим регулярный контроль успешности выполнения СРС и индивидуальные консультации преподавателя. Здесь принципиальное значение имеет личное педагогическое общение преподавателя со студентом;

-для успешности СРС необходимы четкие методические указания по ее выполнению. В начале семестра преподаватель на первом же занятии должен ознакомить студентов с целями, средствами, трудоемкостью, сроками выполнения, формами контроля и самоконтроля СРС. Графики самостоятельной работы необходимы на младших курсах, на старших курсах студентов нужно приучить к планированию собственной работы;

-пакет домашних заданий к практическим занятиям по любой дисциплине должен содержать все типы задач, методами решения которых студенты должны овладеть для успешного прохождения контроля; перечень понятий, фактов, законов и методов, знание которых необходимо для овладения планируемыми умениями, с указанием того, что нужно знать наизусть;

-пакет заданий целесообразно выдавать в начале семестра, оговаривая предельные сроки сдачи;

-при изучении любой дисциплины желательно проводить «входной контроль», лучше всего используя АОС. Такой контроль поможет выявить и устранить пробелы в знаниях;

- задания для СРС могут содержать две части - обязательную и факультативную, рассчитанную на более свободный выбор. 


\section{Литература}

1. Абакумова И.В., Ермаков П.Н., Рудакова И.А. Смыслоцентризм в педагогике. Ростов-на-Дону, 2006.

2. Асланян А.А. Развитие высшего образования в Армении. - Ереван, 2007.

3. Асмолов А.Г. Психология личности. Принципы общепсихологического анализа. - М., 2002.

4. Зимняя И.А. Педагогическая психология. - Ростов-на-Дону, 1997.

5. Матюшкин А.М. Проблемные ситуации в мышлении и обучении. - М., 1972.

6. Педагогика и психология высшей школы. - Ростов-на-Дону, 1998.

7. Смирнов С.Д. Педагогика и психология высшего образования. - М., 2003. 